\title{
Smart Information System for Gachon University Gil Hospital
}

\author{
Dong Kyun Park, MD, $\mathrm{PhD}^{1}$, Eun Young Jung, $\mathrm{RN}, \mathrm{PhD}^{1}$, Byung Hui Jeong, MS ${ }^{1}$, Byung Chan Moon, MS ${ }^{1}$, \\ Hyung Wook Kang, $\mathrm{MS}^{1}$, Hann Tchah, $\mathrm{MD}, \mathrm{PhD}^{2}$, Gi Seong Han, $\mathrm{MS}^{3}$, Woo Sung Cheng, $\mathrm{BS}^{3}$, \\ Young Ho Lee, $\mathrm{PhD}^{4}$ \\ ${ }^{1}$ u-HealthCare Center, ${ }^{2}$ IT Division, Gachon University Gil Hospital; ${ }^{3}$ MCC Inc.; ${ }^{4}$ Department of Information Technology, Gachon University, Incheon, Korea
}

Objectives: In this research, the hospital information system of Gachon University Gil hospital is introduced and a future strategy for hospital information systems is proposed. Methods: This research introduces the development conditions of hospital information system at Gachon University Gil hospital, information about the development of the enterprise resource planning (ERP), a medical service process improvement system, and the personal health record (PHR) system. Results: The medical service process and work efficiency were improved through the medical service process improvement system, which is the most common hospital information system at Gachon University Gil hospital and which includes an emergency medical service system, an online evaluation system and a round support system. Conclusions: Gachon University Gil hospital developed medical service improvement systems to increase work efficiency of medical team and optimized the systems to prove the availability of high-quality medical services for patients and their families. The PHR-based personalized health care solution is under development and will provide higher quality medical service for more patients in the future.

Keywords: Hospital Information System, Quality of Health Care, Electronic Medical Record, Personal Health Record, Management Information System

Submitted: February 17, 2012

Revised: March 24, 2012

Accepted: March 27, 2012

\section{Corresponding Author}

Dong Kyun Park, MD, PhD

u-Healthcare Center, Gachon University Gil Hospital, 21 Namdongdaero, 774 beon-gil, Namdong-gu, Incheon 405-760, Korea. Tel: +82-32-460-8097, Fax: +82-32-460-8098, E-mail: pdk66@gilhospital.com

This is an Open Access article distributed under the terms of the Creative Commons Attribution Non-Commercial License (http://creativecommons.org/licenses/by$\mathrm{nc} / 3.0 /$ ) which permits unrestricted non-commercial use, distribution, and reproduction in any medium, provided the original work is properly cited.

(C) 2012 The Korean Society of Medical Informatics

\section{Introduction}

The modern society has exceeded the concept of 'information-oriented' so that it is called the society of ubiquitous computing, smart computing, and cloud computing. The information technology develops in a way of combining with relevant technology system, and especially, the medical industry business in ubiquitous circumstance drags many attentions about mobile medical information service area [1]. So, the health care field has shown various combinations between the health care and medical technology as it has been called as tele-medicine, tele-health, e-health, m-health, however, since 2000s, it has been unified as the u-health care, which was the combination of ubiquitous and health care. Recently, there are new types of u-health care services 
appear because of the popularity of smart phone and tablet PC.

Based on the cutting-edge technology, the recent trend of hospital is the establishment of new hospital system securing the 'patient-oriented' and 'patient-safety'. To keep pace with and actively lead the trend, Gachon University Gil hospital is making effort to fulfill $\mathrm{u}$-healthcare system, which maximizes the convenience of medical staffs and parents, and improves the quality of medical service by connecting the ubiquitous solution that is one of the newest technologies to medical system. Gachon University Gil hospital conducts various researches combining medical and IT technologies, and the result is applied to the field. By these effort, Gachon University Gil hospital turning into the best hospital providing the best medical service to patients [2]. Hospital information department has been equipped with new mainframe, implementing main system from data general in 1985 and 1987. In March 1987, as Gil hospital order communication system (OCS) has been implemented to input prescription. In addition, medical image information system, remote service system, resource management system and electronic medical card system has been implemented in order.

This study introduces Gachon University's information system and system for work process improvement and personal health record (PHR) system, basis of self health management service system.

\section{Case Description}

\section{Architecture of Gil Hospital Information System}

The information system of Gachon University Gil hospital consists of OCS, electronic medical record (EMR) system, picture archiving and communication system (PACS), enterprise resource planning (ERP) system, data warehousing (DW) system and web system.

Hospital information system should collect, manage and use enormous quantity of data. Figure 1 is overall architecture of the information system for Gachon University Gil hospital. The information system of Gachon University Gil hospital is connected organically. So the data, which is created in the administration, is collected at the final destination, ERP and DW, and the group ware has been built to assist decision making.

Figure 2 is the hardware architecture of Gil hospital information system. The system of OCS and EMR consist of database application and file server. The database server is dualized by coupling Unix OS and Sybase database on the IBM AIX (HACMP), the application server and file server are based on Microsoft Windows which are dualized (Microsoft cluster service, MSCS).

The ERP system uses OracleR11i package, and the operation server consists of Unix OS and Oracle DB on the IBM AIX server so that the database and application are operated on the identical server.

The DW system consists of data storage enterprise application integration (EAI) tool, Business Objects OLAP tool, and Oracle database. The DW server consists of Unix OS on the IBM AIX and the Business Objects have been built for Windows.

PACS system consists of database, storage, and application and the dataset server has been built on the IBM AIX using Oracle. The storage consists of IBM NS6040 (NAS) and the

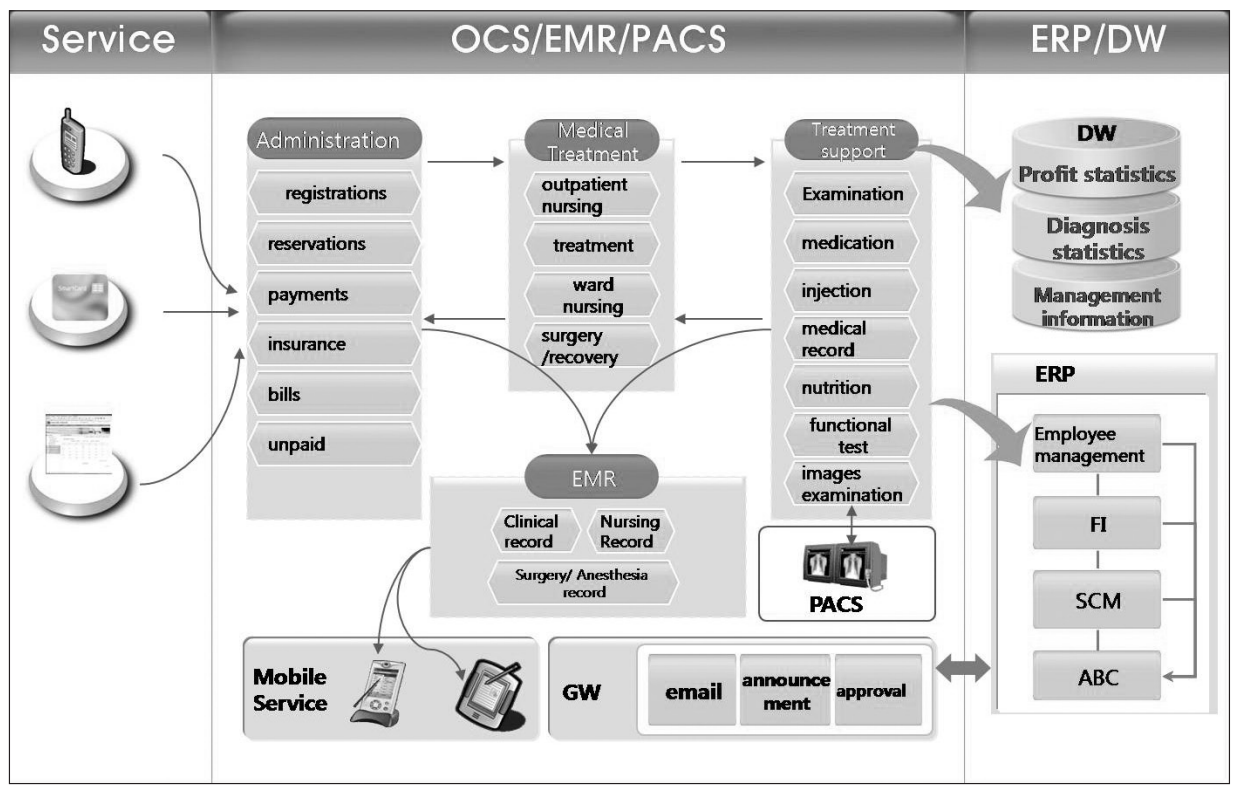

Vol. 18 • No. 1 • March 2012 www.e-hir.org 


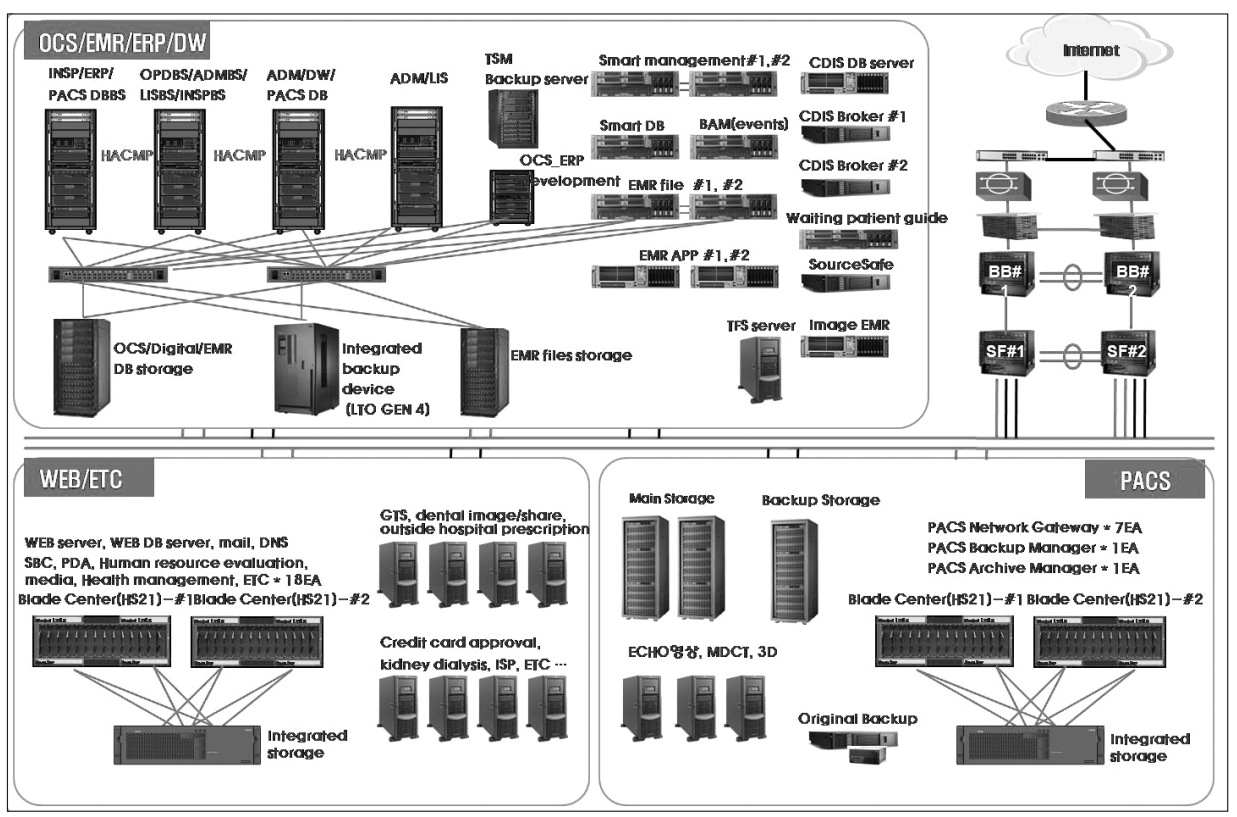

Figure 2. Hardware structure of Gil hospital information system. OCS: order communication system, EMR: electronic medical record, ERP: enterprise resource planning, DW: data warehousing, PACS: picture archiving and communication system.

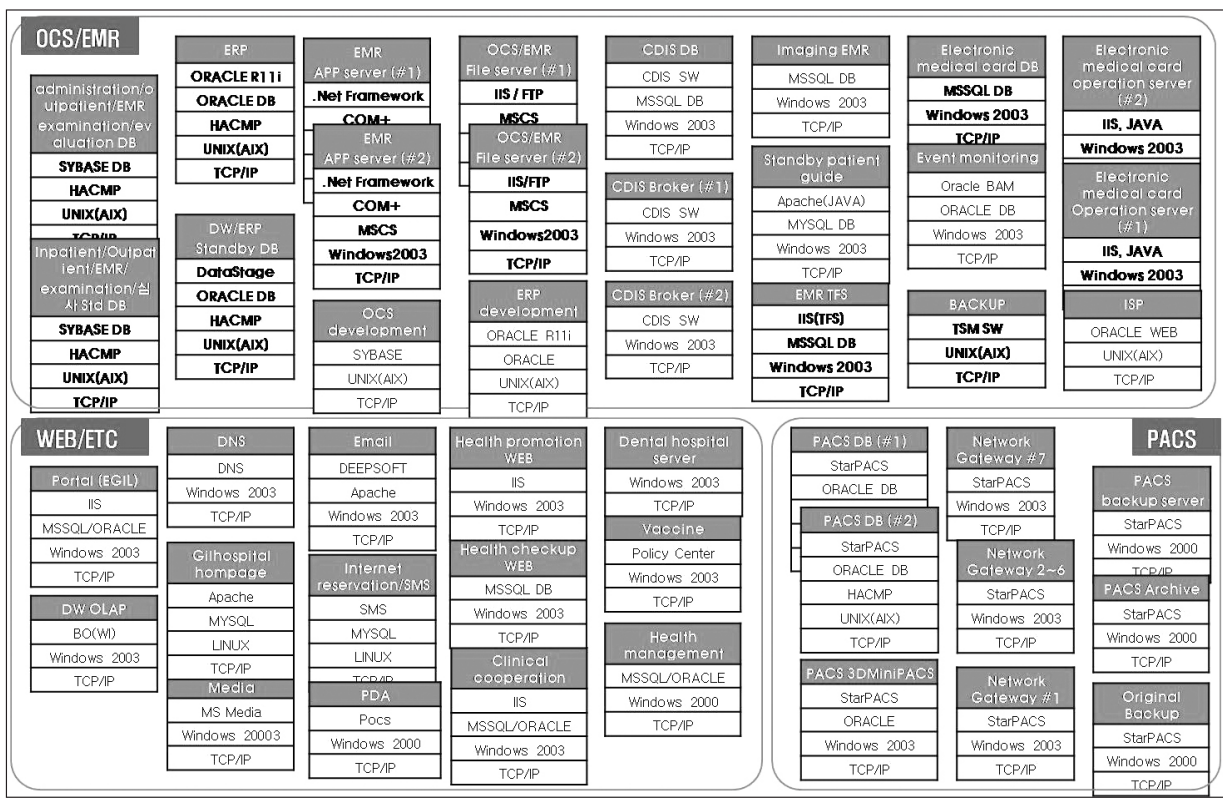

Figure 3. Software structure of Gil hospital information system. OCS: order communication system, EMR: electronic medical record, PACS: picture archiving and communication system.

application has been integrated on the BladeCenter in Windows circumstance.

Web system also uses Windows server. The Web Server mainly consists of internet information server (IIS) and database consists of Microsoft structured query language (MSSQL), and both of them are integrated on the BladeCenter to save the space and cost.

The software for Gachon University Gil hospital information system has been built considering characteristics of each work. Like hardware system, the software system has been also divided in the OCS, EMR service, PACS service and Web service, and its construct has been shown for each of works,
The EMR system consists of three tiers. The database uses Sybase, the application consists of COM+ of .Net Framework and ADO.Net, and the user interface has been developed by Win Forms on the .Net Framework.

The OCS system consists of two tiers. The database uses Sybase, the Business logic mainly processes by stored procedure and the user interface has been developed using Visual Basic.

The ERP system consists of three tiers. The database is based on Oracle and Oracle application R11i package provides business logic process and user interface.

The PACS system consists of two tiers. The data based is based on Oracle and the user interface has been developed 
by $\mathrm{C}++$ and uses the network access server (NAS) storage.

The Web system consists of three tiers. The system circumstance differs by characteristics of each work but database for most of systems is based on the MS-SQL. The Web server uses IIS and the user interface has been developed by the active server page (ASP).

The most important evaluation index for hospital information system management is system operation rate. The hospital has very special work condition that must be operated for 365 days in a year without a break, because of the special characteristic of its work. Because of this trend of system, OCS, EMR system, PACS, and network operation rate are important items for medical service evaluation at a hospital. Figure 3 shows software architecture of Gil hospital's information system.

\section{Characteristics of Gachon University Gil Hospital's Hospital Information System}

Gachon University Gil hospital integrated its data through digital hospital project. Digital hospital project was started in 2004 through 2005 in cooperation with MCC and Oracle. Objectives of digital hospital project was to establish ERP and DW that include financial accounting (FI), supply chain management (SCM), activity based management (ABM), balanced score card (BSC) and data integrations between systems were essential task.

Cash recipients system was needed to convert to accrual accounting in accountancy system for data integration. Data alteration management system was applied to OCS and EMR data to establish occurrence base system. Data alteration management system creates one record of data, two altered data and one delete data per occurrence date. Data alteration management reduces ERP and DW system load by stacking only end date data.

Data integration was done in five phases. Data alteration management and distributed financial processing settlement management of accounts were applied in the first step. Enterprise data warehousing (EDW), which previous data and new data created through data cleansing by data alteration management were established in the second phase. Data interface were established in the third stage by establishing data mart (DM) per subject category, ERP SCM and FI module for on data in EDW.

By establishing ERP, pre-management system were established by providing financial information timely, which enables efficient fund management by occurrence based daily profit management and fund forecast by planning income and expenditure.

\section{Results}

Gachon University Gil hospital established systems to improve diagnosis process for patients' safety and efficient work after data and system integration through digital hospital project. Representative systems for process improvements are medical service system for emergency patients, online

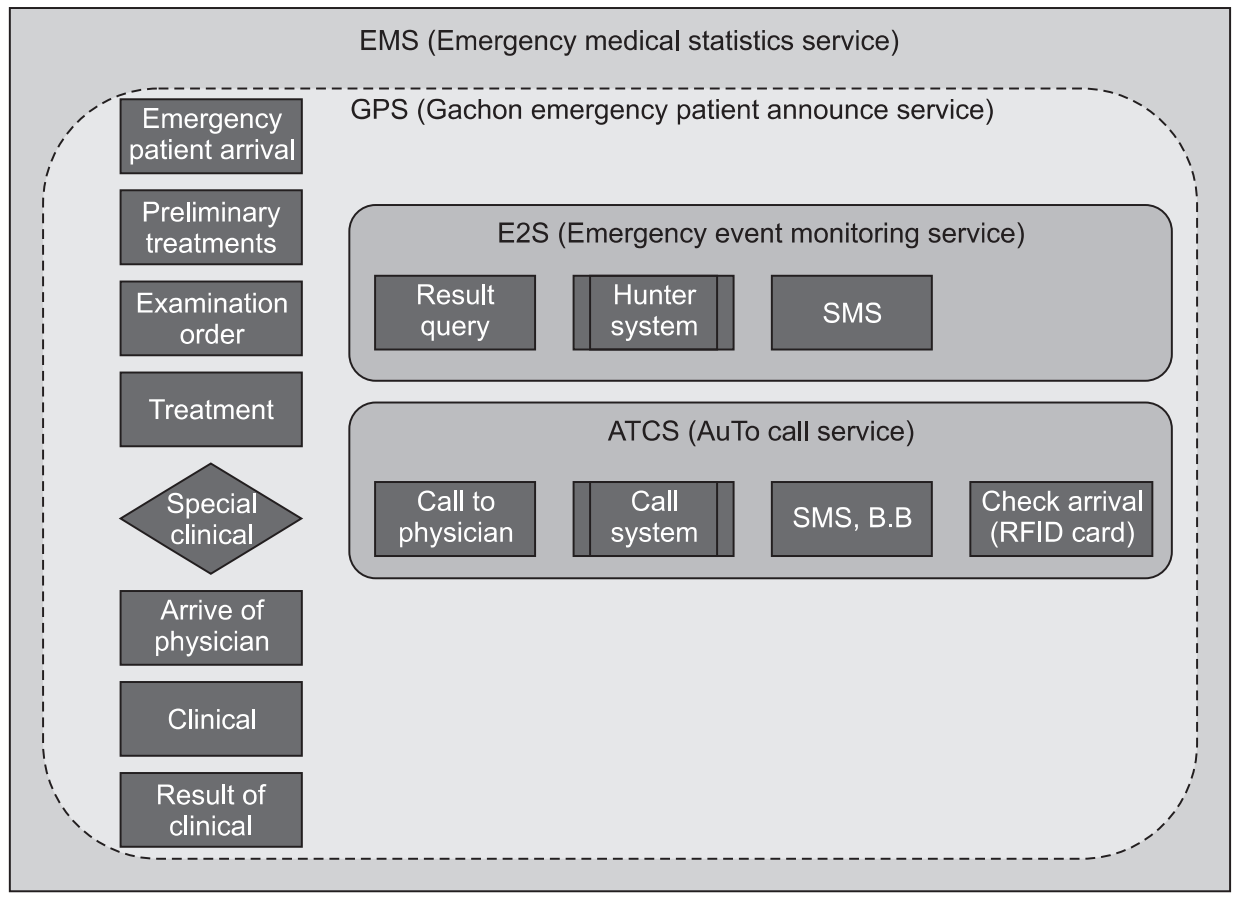

Vol. 18 • No. 1 • March 2012
Figure 4. Emegency system structure. SMS: short message service, RFID: radio frequency identification. 
diagnosis system to support prescriptions based on previous subscriptions, and the mobile round support system.

\section{Emergency Medical Service System}

The medical information system for emergency patients is integrated information system to manage patients in emergency and severity, who take medical service at Gachon University Gil hospital emergency medical center. Figure 4 shows the structure of medical service system for emergency patients. Medical service system for emergency patients have auto call service (ATCS), emergency event monitoring service (E2S) and emergency patient announce service (EPS) is additionally built to conduct core functions of emergency medical system.

ATCS system automatically calls doctors of each department to the emergency center after the initial medical service. The system constantly calls doctor to come and treat patients through short message service (SMS) and beeper, until called doctors arrive at the emergency center and check their arrival with own radio frequency identification (RFID) card. Using the ATCS, wasted time to find proper doctors at emergency center has been redirected to be used to treat patients for medical service.

E2S is an alarm system to notify problems through web display, when emergency patients have problems during medical examination. The E2S system is an online system to let

\begin{tabular}{|c|c|c|c|c|c|c|c|c|}
\hline & & & & $\begin{array}{c}\text { chon L } \\
\text { Em }\end{array}$ & & y $\mathbf{G}$ & $\begin{array}{l}\text { Hospital } \\
\text { er }\end{array}$ & \\
\hline 2012年 01月 & 10 日 1 & 1:06 & & & & & Bedo & upancy : $25 / 30$ \\
\hline Name & \begin{tabular}{|l} 
Age \\
Sex
\end{tabular} & Area & $\begin{array}{l}\text { Visit } \\
\text { time }\end{array}$ & X-Ray & CT & LAB & Department & Status \\
\hline Patient A & F/94 & 0 & 09:26 & 0 & & 0 & EM & Treatment \\
\hline Patient B & M/13 & T & $09: 45$ & & & & EM & Treatment \\
\hline Patient C & M/19 & B & 09:49 & 0 & & 0 & EM & Treatment \\
\hline Patient D & F/17 & B & 10:06 & 0 & & 0 & EM & Treatment \\
\hline Patient E & $M / 51$ & $\mathbf{R}$ & 10:17 & 0 & 0 & ○ & IM & $\begin{array}{c}\text { Joint } \\
\text { Treatment }\end{array}$ \\
\hline
\end{tabular}

Figure 5. Emergency patient announcement system.

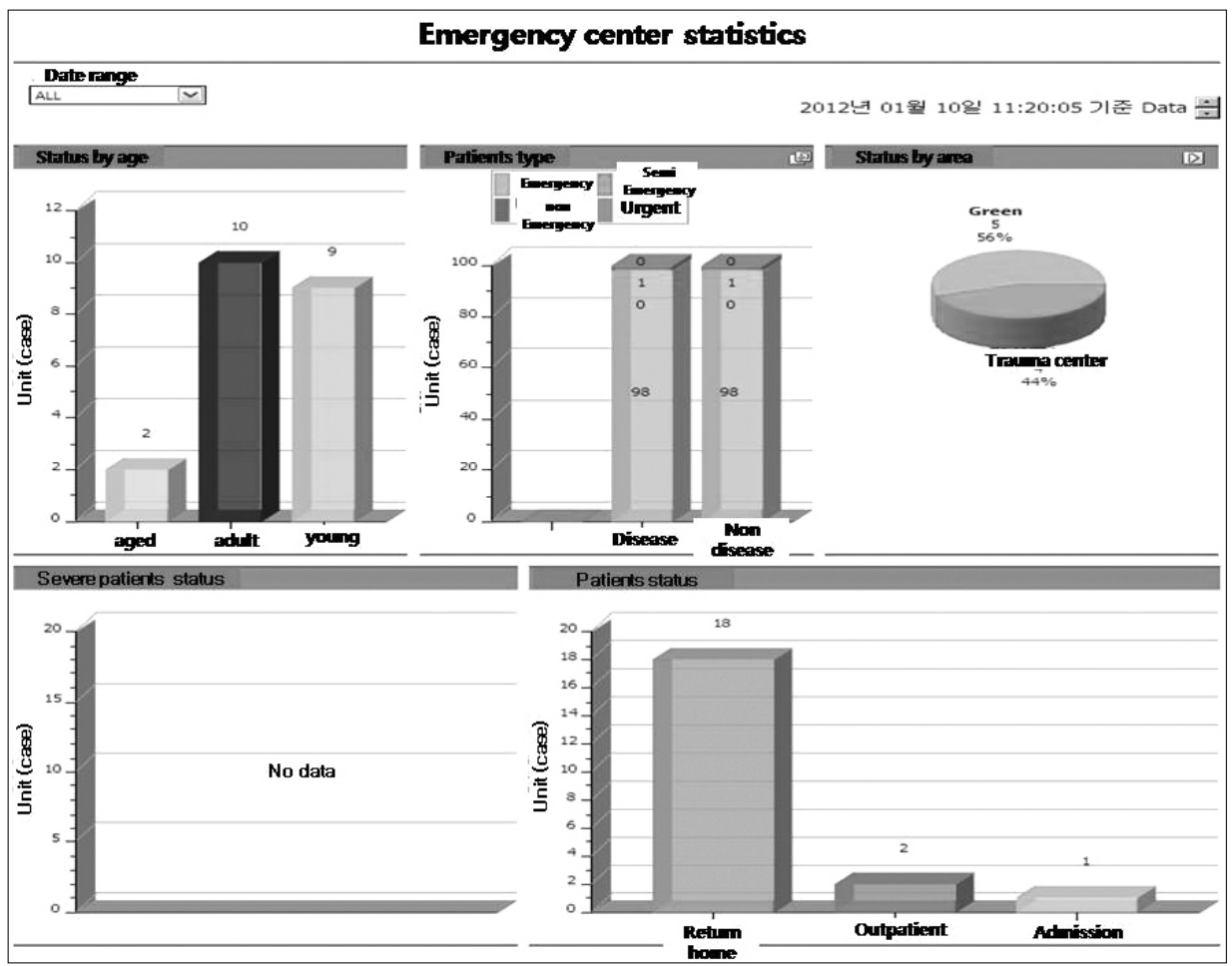

Figure 6. Emergency medical statistics service. 
doctors know when visited patients have medical problems. It shows examination results and patients list in real-time, when they are out of normal range.

The EPS shows visited patients list of emergency center, districts for each patient, progress of X-ray, computed tomography (CT), LAB test, areas of medical service, and examination result, on the programmed data processor (PDP) display. Also, since most of patients visit hospital with their guardians, notices for guardians and status of usable hospital beds at emergency room are displayed. As shown on Figure 5, Among arrived patients, patients who are in urgent for their vitality are allocated at area $\mathrm{R}$ (intensive care room), patients of serious cases are allocated at $\mathrm{O}$ (orange) and $\mathrm{Y}$ (yellow), children patients are allocated at G (green), patients of medical cases are allocated at B (blue), patients having external injury are allocated at $\mathrm{T}$ (external injury treatment room),

Table 1. Online diagnosis check index

\begin{tabular}{ll}
\hline \multicolumn{1}{c}{ Category } & \multicolumn{1}{c}{ Detail } \\
\hline $\begin{array}{l}\text { Approved items } \\
\text { Approved items by the medical insurance. It is to be error when other items happen except the } \\
\text { approved. }\end{array}$ \\
$\begin{array}{l}\text { It is to be error when items that are not approved by the medical insurance happen. } \\
\begin{array}{l}\text { Index items of authoritative } \\
\text { interpretation }\end{array}\end{array}$ \\
$\begin{array}{l}\text { Items are selected by conditions and they follow index items authoritative interpretation. } \\
\text { Approval support items }\end{array}$ \\
$\begin{array}{l}\text { Approved when it follows a } \\
\text { standard amount }\end{array}$ & It is approved when the quantity of occurred items follows a standard. \\
\hline
\end{tabular}

Table 2. Simplicity items of online diagnosis

\begin{tabular}{|c|c|}
\hline Items & Explanation \\
\hline Daily maximum dose & $\begin{array}{l}\text { The daily maximum dose of medicines for the effect, quantity, and usage that are } \\
\text { approved by the Ministry of Health and Welfare. }\end{array}$ \\
\hline $\begin{array}{l}\text { Maximum days of execution for medi- } \\
\text { cal service }\end{array}$ & $\begin{array}{l}\text { Maximum days of medical executions during hospitalization. Ex) only three Flagyl's } \\
\text { are allowed for } 7 \text { days and it occurs an error when it occurs for } 8 \text { days. }\end{array}$ \\
\hline Approved period and maximum dose & $\begin{array}{l}\text { The maximum days of treatment and dose during hospitalization. Ex) only three } \\
\text { Flagyl's are allowed for } 7 \text { days, and it causes an error when it occurs for } 8 \text { days or its } \\
\text { number exceeds three. }\end{array}$ \\
\hline $\begin{array}{l}\text { Categorization code } \\
(\mathrm{IM} / \mathrm{IV} / \mathrm{IA} / \mathrm{PO} \ldots)\end{array}$ & $\begin{array}{l}\text { It manages items for each category. Ex) when a medicine for the external is used } \\
\text { during the internal medicine use, an error occurs. }\end{array}$ \\
\hline Sex & Items for male and female are managed including the sick and wounded. \\
\hline Age limit & $\begin{array}{l}\text { Infants, children, adults and elders are manages by their ages (under or over an } \\
\text { index age). }\end{array}$ \\
\hline Appendix & $\begin{array}{l}\text { Appendix data is managed for each item after treatments or tests. Ex) the usage result } \\
\text { should be included when the albumin has been used. The opinion should be for a } \\
\text { computed tomography scan. }\end{array}$ \\
\hline Category of clinical materials & The clinical materials for daily trials and number of trials are managed. \\
\hline $\begin{array}{l}\text { Category of clinical materials } \\
\text { during medical service period }\end{array}$ & $\begin{array}{l}\text { The maximum number of clinical materials and trial number during hospitalization } \\
\text { are managed. }\end{array}$ \\
\hline Medical service type & Items for a visit (hospitalization) or out-patient treatment are managed. \\
\hline Prescription occurrence interval & It manages prescription order occurrence interval during hospitalization \\
\hline Application for medical service period & $\begin{array}{l}\text { It manages the medical service period during the hospitalization. The dose has been } \\
\text { managed for application, period, and interval of medical service. }\end{array}$ \\
\hline
\end{tabular}


patients of light case are allocated at F (triage room), and patients with contagious disease are allocated at I (isolation room). Figure 6 is the displayed result of EMS systems provides status of ages, classes, each districts, case kinds for each serious case, and emergency patients process, are displayed in a form of graph in real-time.

To inform status of patients, automatic examination alarm service has developed, so that doctors can recognize the problems. For guardians, service progress status is shared through automated system, and medical staffs became to have higher concentrations.

\section{Online Review System}

The online review system is an advanced prescription process system to support that a doctor does not make medical errors when they prescribe online. Items for online review system consist of simplicity item and variety item. Detailed information about each item is on Table 1.

The items for online review are divided in to simplicity items and variety items are as shown in Tables 2 and 3. The online review shows the prescription index information and the approval index of medical insurance for the error check, and it also allows looking for the information about the sick and wounded when error occurs for the information. When there is an item with errors during the online review, the prescription for the patient is not allowed to be inserted and the prescription or the title of sickness should be changed in accordance with the registered information of online review master. The online review checks inserted prescriptions on the display and the history to check errors.

By adopting online review system, factors that the Health Insurance Review \& Assessment Service can cut the medical expense claim are prevented, so that the loss decreases. It also improves the quality of work through system automation and so that the rolls of members in charge of the review have been changed from the functional to analytic process. Also, online review was established to pre-manage prescriptions and minimize review and waiting time for discharge patients.

\section{Round Support System}

Medical staffs continuously move in the hospital for rounds, surgery room for the surgery, doctor's office for the outpatient clinic, and others for various reasons. They do not simply stay at a spot for a group of patients. Considering these medical circumstances, the round support service system has been developed so that doctors can provide medical service at Gachon University Gil hospital through WIFI or $3 \mathrm{G}$ networks, which could not be done without PC. Hospital information system and user interface should support much information on the display. Thus it was built on the Galaxy tab. Figure 7 shows system composition of round support

Table 3. Variety items of online diagnosis

\begin{tabular}{|c|c|}
\hline Items & Explanation \\
\hline Medical service department & $\begin{array}{l}\text { The daily maximum dose of medicines for the effect, quantity, and usage that are } \\
\text { approved by the Ministry of Health and Welfare. }\end{array}$ \\
\hline Occurrence of the first fee code & $\begin{array}{l}\text { The maximum days of treatment and dose during hospitalization. Ex) Only three } \\
\text { Flagyl's are allowed for } 7 \text { days, and it causes an error when it occurs for } 8 \text { days or } \\
\text { its number exceeds three. }\end{array}$ \\
\hline The fee code after the surgery & $\begin{array}{l}\text { It manages items for each category. Ex) when a medicine for the external is used } \\
\text { during the internal medicine use, an error occurs. }\end{array}$ \\
\hline Fee (ingredient) code & Items for male and female are managed including the sick and wounded. \\
\hline Essential fee code & $\begin{array}{l}\text { Infants, children, adults and elders are manages by their ages (under or over an } \\
\text { index age). }\end{array}$ \\
\hline $\begin{array}{l}\text { Request for the main prescription when } \\
\text { the simultaneous prescription exists }\end{array}$ & $\begin{array}{l}\text { Appendix data is managed for each item after treatments or tests. Ex) the usage result } \\
\text { should be included when the albumin has been used. The opinion should be for a } \\
\text { computed tomography scan. }\end{array}$ \\
\hline $\begin{array}{l}\text { Request for the alternative when the } \\
\text { simultaneous prescription exist }\end{array}$ & The clinical materials for daily trials and number of trials are managed. \\
\hline Substitutable items & $\begin{array}{l}\text { The maximum number of clinical materials and trial number during hospitalization } \\
\text { are managed. }\end{array}$ \\
\hline Substitute for the sick and wounded & Items for a visit (hospitalization) or out-patient treatment are managed. \\
\hline
\end{tabular}




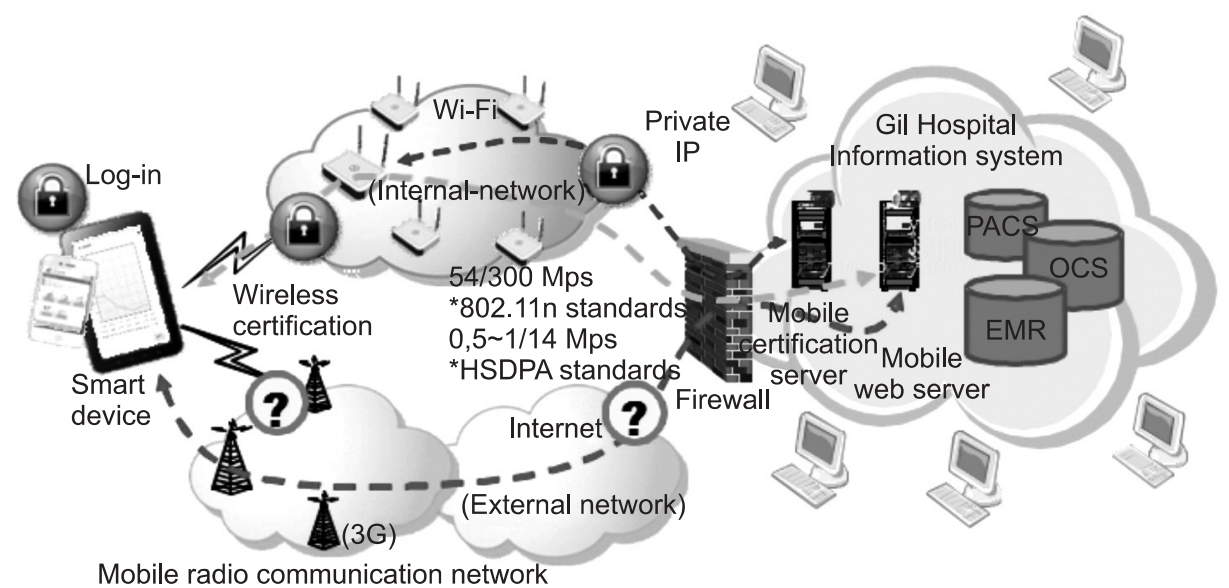

Mobile radio communication network

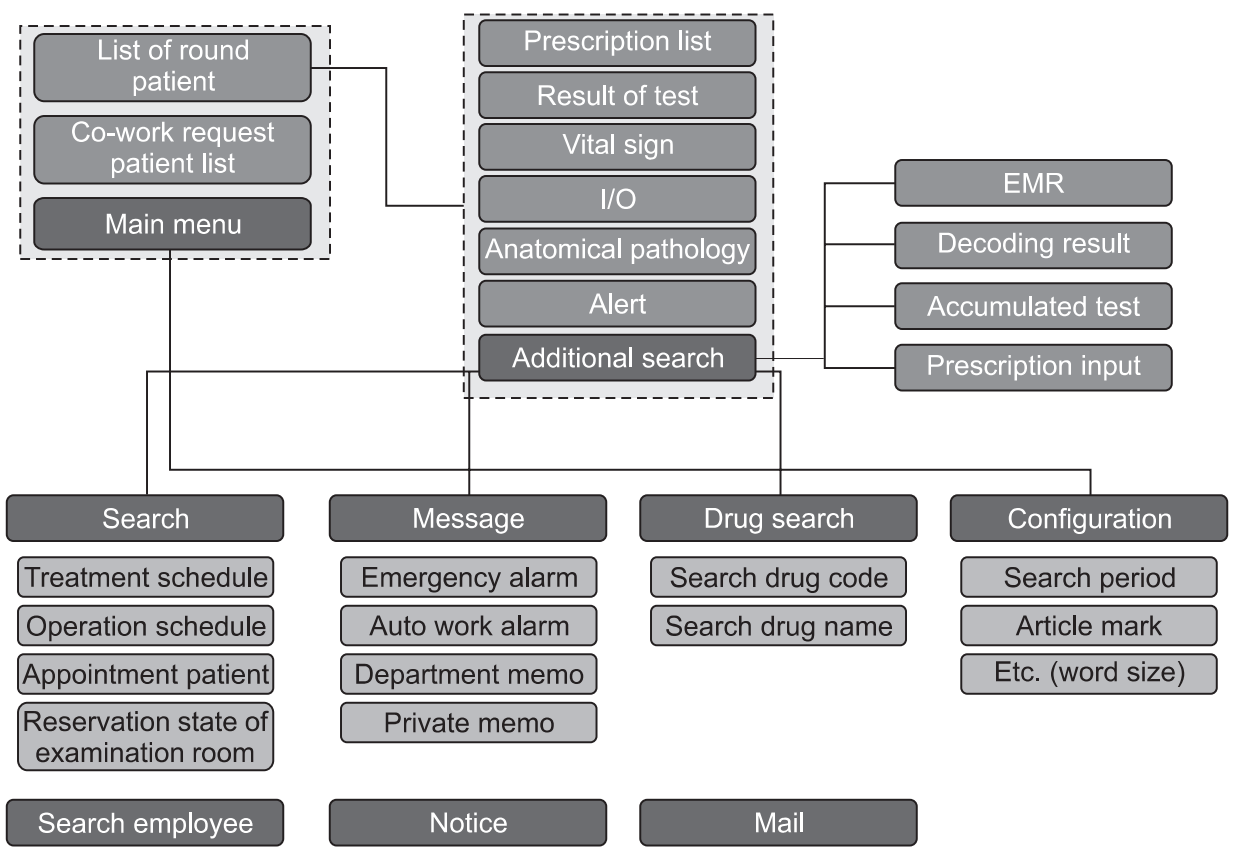

Figure 7. System composition of round support system.
Figure 8. Structure of round support system. I/0: input/output, EMR: electronic medical record. system.

In the past, mobile devices could connect to the medical information through closed wireless network, so that security issues were not critical. However, current mobile devices supports open mobile network, such as $3 \mathrm{G}$, security problems can occur. To solve this problem, the mobile certification process has been built and only registered mobile devices in certification server can access to medical information.

The round support system, which was developed to promote efficiency of medical service, built mainly based on functions, which can be used during rounds for patients. With round support system, doctors can handle processes, which should have done with personal notes and PC, with mobile devices. In the past, medical staffs sometimes waited to use PC, however, these cases are decreasing after adopting round support system.

The messaging functions of round support system can manage emergency inform or call and personal workflow, and it enables medical team to response to requests of medical service cooperation, more rapidly. Figure 8 shows the overall menu structures of round support system.

\section{Discussion}

Establishing hospital information system is focused on providing the best service for patient and improvement of medical service. There are wide ranges of domestic and international researches to adapt economic and effective technology to hospital information system. The information flow connects between departments of hospital and different hospitals [3]. Because of the increase of needs in health manage- 


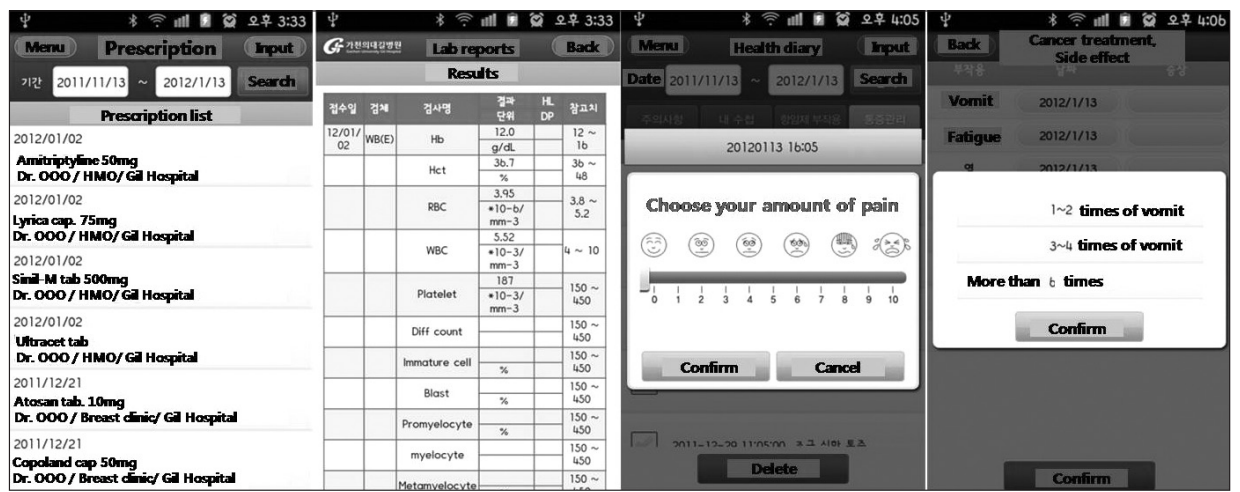

Figure 9. Output displays of of uCAREnote.

ment service, the circumstance of health and medical care service needs interactions between people and hospitals. To reflect these changes of health and medical care services and provide comprehensive medical service focused on the quality of life, the system, such as PHR to collect lifetime health record is required [4]. PHR can decrease medical accidents and overall cost of health management as well as improves cooperation between patients and doctors through communications for personal disease care and treatment [5]. PHR can also be utilized to evaluate the completion and precision of medical information relevant to the remedy and test trial for specified diseases [6]. Especially, doctors think that the system with PHR is effective to improve quality and satisfaction about medical services [7]. PHR becomes an important medical basis for personalized medical service to understand characteristics of a person and choose appropriate remedy or prescribe medicine [8].

Along with the current trend of health and medical service, Gachon University Gil hospital developed personalized medical service, $\mathrm{u}$-CAREnote, which is based on PHR. Since January 2012, the service started to provide personal disease history, medical administration record, test record, record of treatment and surgical procedures, surgery record and information about anticancer and radiation treatments for patients having cancers. Also, personal memo system, which is a health diary for side-effect of anticancer drug and pain management, is supported for self-management of cancer patients. Figure 9 shows output displays to manage medical administration of u-CAREnote, test result, cancer pain management, and anticancer drug side-effect management.

For interactions to expand and propagate PHR and exchange the PHR information, Gachon University Gil hospital started a research to establish PHR standardization and platform connecting with Seoul University Hospital, Ajou University Hospital, Busan University Hospital, and Korean Associations of Regional Public Hospitals.

Finally, health management services such as the PHR based personalized diet and exercise services are developed, patients using u-CAREnote can have high quality health care service. Also, home nursing service to provide medical service at home and home monitoring service keep being developed to provide the best medical service for patients.

\section{Conflict of Interest}

No potential conflict of interest relevant to this article was reported.

\section{Acknowledgments}

This study was supported by a grant of the Korean Health Technology R\&D Project, Ministry of Health \& Welfare, Korea (A112020). This work was supported by grant no. 10037283 from the Industrial Strategic Technology Development Program funded by the Ministry of Knowledge Economy.

\section{References}

1. Lee TK. Status of present medical information system and future strategies. Korean Soc Comput Inf Rev 2011; 19:1-11.

2. Shin JW. Gachon University Gil hospital, leading medical and IT convergence. Korea Inf Sci Soc Rev 2010; 28:106-9.

3. Chung DG, Kim KH, Kim MG. The study on computer network for medical application. Annu Bull Inst Hosp Manag 1995;1:51-75.

4. Park YM, Oh YH. A Study on the integration of healthcare information system based on SOA for PHR services. J Korean Inst Electron Eng 2011;48:136-42.

5. Reti SR, Feldman HJ, Safran C. Governance for personal health records. J Am Med Inform Assoc 2009;16:14-7.

6. Kim MI, Johnson KB. Personal health records: evalua- 
tion of functionality and utility. J Am Med Inform Assoc 2002;9:171-80.

7. DesRoches CM, Campbell EG, Rao SR, Donelan K, Ferris TG, Jha A, Kaushal R, Levy DE, Rosenbaum S, Shields AE, Blumenthal D. Electronic health records in ambulatory care: a national survey of physicians. $\mathrm{N}$ Engl J Med 2008;359:50-60.

8. Lee SW, Lee KB, Kang JW, Choi JC, Oh JH. Trends in personalized medicine research. Korean Inf Sci Soc Rev 2011;29:19-25. 